\title{
Intention to Use Renewable Energy: Mediating role of Attitude
}

\author{
${ }^{1}$ Syed Shah Alam and ${ }^{2}$ Mamunur Rashid \\ ${ }^{1}$ School of Management, Faculty of Economics and Management, \\ ${ }^{2}$ Graduate School of Business, \\ Universiti Kebangsaan Malaysia, Bangi, Selangor, Malaysia 43600, Malaysia
}

\begin{abstract}
Acceptance of renewable energy is influenced by attitude of the users towards new technology. Lack of research on renewable energy in emerging countries and drive for switching to alternative energy urge for studies on attitude of the users' towards renewable energy adoption. This study investigates perception towards renewable energy use in Malaysia. A survey over 200 respondents from Klangvalley area was analysed using exploratory factor analysis and multiple regression analysis. Five factors emerged from factor analysis are relative advantage, perceived behavioural control, ease of use, awareness and benefit-cost trade-off. Multiple regression analysis was conducted to examine the explanatory power of these five factors while predicting intention to use renewable energy. The analysis showed that relative advantage and perceived behavioural controls positively mediate attitude towards renewable energy and attitude positively mediates intention to use. However, ease of use, benefit-cost trade-off and awareness positively but directly influence intention to use renewable energy. Study contributes to the literatures on social barriers of renewable energy in emerging nations and theory of planned behaviour. It contributes to existing policy initiative taken by government to enhance the use of renewable energy in Malaysia.
\end{abstract}

Keywords: Renewable Energy, Alternative Energy, Malaysia, Attitude, Theory of Planned Behaviour, Relative Advantage, Directly Influence Intention

\section{INTRODUCTION}

Higher dependency of the use of fossil fuel has resulted in increasing global warming. From the standpoint of alternative energy solution, one of the regular ways to solve the global warming problem is to invest in and socialise the use of renewable energy among mass users. Data from department of statistics Malaysia (Table 1) shows that around thirty per cent of Malaysia's export and fifteen per cent of Malaysia's import involves non-edible and petroleum oil to provide energy solution. However, attempt to convert to renewable energy has been very slow worldwide. Renewable energy initiative, REN21 (2011) reports that the initiative of country-wide investment in renewable energy is limited only among top five countries in the world. A presentation (Fig. 1 and 2) from energy commission Malaysia reveals a startling picture depicting Malaysia's growing need for energy and insignificant influence by renewable energy initiative. A growing body of studies on alternative energy criticises limited information on the customers' attitude towards renewable energy for not having successful penetration among the users.

An important body of literatures examines various factors influencing customers' intention to use renewable energy. These literatures from western contexts investigate how various social, political and financial issues turn into expensive choices for the users of renewable energy. Studies on social acceptance of renewable energy in Malaysia involve technical and regulatory features of various energy sources (i.e., solar, biomass).

Corresponding Author: Syed Shah Alam, School of Management, Faculty of Economics and Management, Universiti Kebangsaan Malaysia, Bangi, Selangor, Malaysia 43600, Malaysia 
Hydropower $\square$ Coal and coke $\square$ Natural gas $\square$ Petroleum products and others $\square$ Crude oil

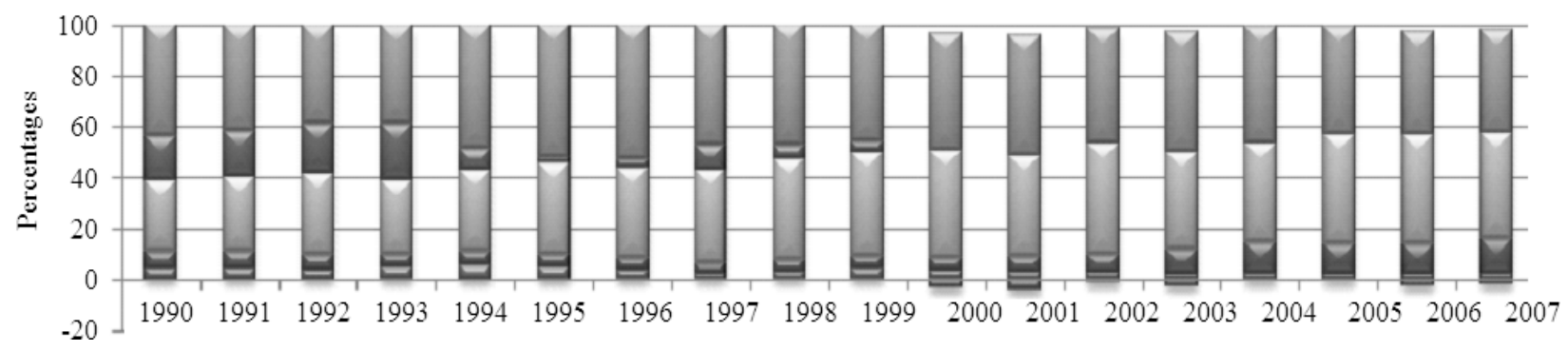

Fig. 1. Commercial energy supply in Malaysia Source: Energy Commission Malaysia

Ginal energy demand (ktos) $\quad$ Final energy supply (ktoe)

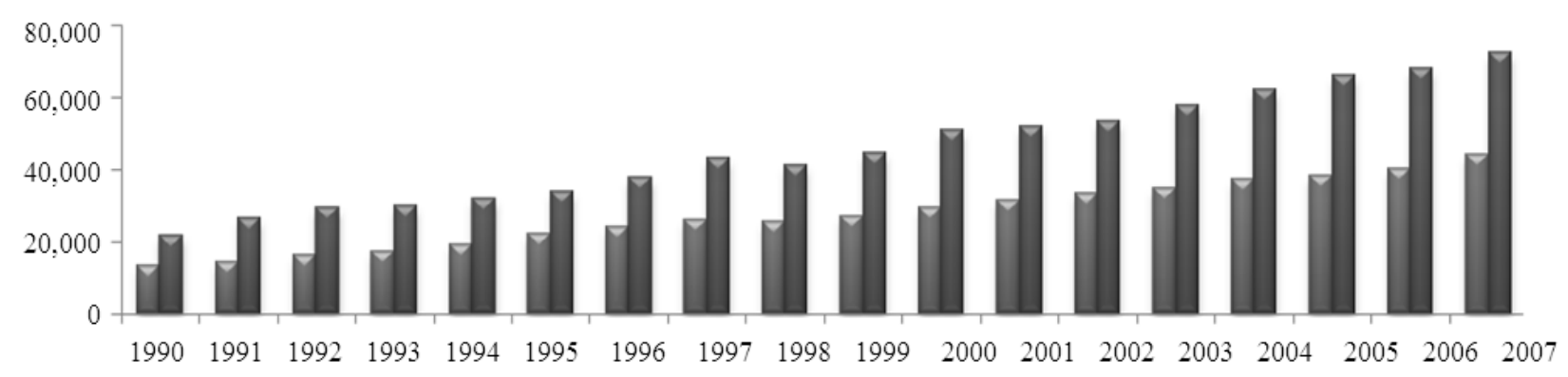

Fig. 2. Primary energy supply and demand in Malaysia Source: Energy Commission Malaysia

Table 1. Selected economic indicators of Malaysia

\begin{tabular}{|c|c|c|c|}
\hline Indicators & 2008 & 2009 & 2010 \\
\hline GDP at current prices (RM million) & $742,470.0$ & $679,938.0$ & $765,965.0$ \\
\hline GDP Growth (\%) & 4.8 & $(1.6)$ & 7.2 \\
\hline Import (total import as a percentage of GDP) & $70.0 \%$ & $64.0 \%$ & $69.0 \%$ \\
\hline Crude materials, inedible ( $\%$ of total import) & $4.0 \%$ & $3.0 \%$ & $4.0 \%$ \\
\hline Mineral Fuels, Lubricants and other ( $\%$ of total import) & $11.0 \%$ & $8.0 \%$ & $10.0 \%$ \\
\hline Oils and animal and vegetable fats (\% of total import) & $1.0 \%$ & $1.0 \%$ & $1.0 \%$ \\
\hline Total (sum of $\% 1-3$ ) & $16.0 \%$ & $13.0 \%$ & $15.0 \%$ \\
\hline Export (total export as a percentage of GDP) (\%) & $89.0 \%$ & $81.0 \%$ & $83.0 \%$ \\
\hline Crude materials, inedible (\% of total export) & $3.0 \%$ & $2.0 \%$ & $3.0 \%$ \\
\hline Mineral fuels, lubricants and other ( $\%$ of total export) & $18.0 \%$ & $14.0 \%$ & $16.0 \%$ \\
\hline Oils and animal and vegetable fats ( $\%$ of total export) & $9.0 \%$ & $8.0 \%$ & $8.0 \%$ \\
\hline Total (sum of \% of $1-3)(\%)$ & $30.0 \%$ & $25.0 \%$ & $27.0 \%$ \\
\hline
\end{tabular}

Source: Department of statistics Malaysia (Malaysia at a glance), visited on march 2012

As the demand for energy in emerging nations is increasing tremendously, it is of immense importance to understand the users' attitude towards and intention to use renewable energy.

Cost reduction, users' life standard, location of the users' establishment and users' knowledge gap emerge as significant determinants of the users' intention to use renewable energy. Most of these factors are examined based on post-purchase behaviour of the users of renewable energy. Moreover, the pre-purchase users' intention primarily concentrated predominantly towards willingness-to-pay syndrome. Majority of the studies have reported using innovation diffusion theory by Rogers et al. (2008), which considers adoption to renewable energy technology continuing procedure. However, it is yet to fully uncover the theoretical basis 
of pre-purchase decision making in renewable energy. This study combines theories from the core of prepurchase intention, underlying reasons behind any decision and adoption to new technology. This study intends to identify the factors influencing the intention to use renewable energy in Malaysia.

Renewable energy is the transformation of natural energy with the help of advanced technology to replace conventional energy solutions to reduce the global warming problems. Last two decades, from 1990-2010, experience a number of studies that have been conducted to identify factors influencing attitude of the potential users' towards renewable energy in different western countries. These factors can be classified into three major groups: social, political/regulatory and technical. However, Fredric and Martinot (2004) Jacobsson and Johnson argue that social awareness and lack of understanding of the choice of the end users are among the important reasons behind the slow growth of renewable energy revolution in many countries. Extant studies investigated two dimensions of theories while looking into factors influencing the attitude of the end users: the pre-purchase and the post-use behaviour. Since, it is important for various emerging nations to understand the transmission process from conventional to renewable energy, this study reviews factors and theories relevant to pre-purchase attitude towards renewable energy use.

What are the usual suspects while investigating end users' purchase intention of the new technology? Two groups of theories are highly cited in this regard. Theory of Reasoned Action (TRA) and Theory of Planned Behaviour (TPB) in one group and Technology Adoption Model (TAM) in another group. Fishbein and Ajzen (1975) and Ajzen $(2002$; 1991) provide framework for systematic purchase decision process using TRA and TPB respectively. These two theories explain norms and behavioural control of the users into action. Technology Adoption Model advances on the theory of reasoned action; however, put aside the influence of norms. Technology adoption model put forward more extrinsic variables based on perceived usefulness and perceived ease of use influencing attitude towards any product. TRA and TPB combine extrinsic and intrinsic variables that involve subjective norms alongside attitude towards behaviour as determinants of behavioural intention. Two major differences between these two groups of theories are attitude being a mediator in technology adoption model and normative belief and perceived users' behavioural control becoming separate determinants in theory of reasoned actions and theory of planned behaviour.
Attitude towards renewable energy can be defined as the perception of the potential users', their belief about the benefits and drawbacks of the new technology and about their intention to buy the technology. Renewable energy is expensive. However, the benefits are enduring as well. Hence, the potential must have correct information and must have adequate level of awareness to make the best trade-off between the benefits and drawbacks of the renewable technology. Renewable technology awareness is concept where potential users' can collect or have access to necessary information about the basic use, financial prospects and environmental impact of renewable energy. Higher level of awareness enables the users' making informed decision and increases the level of acceptance among new users. To make information cheap and accessible by mass users, government can undertake extensive marketing plans. Large scale training and community awareness programs can be carried out to facilitate an easy transition from conventional to renewable energy solutions:

H1: A higher level of technology awareness has positive relationship with users' intention to use renewable energy.

After analysing the preliminary information on renewable energy information, users' collect information on cost of installation of the new machines, maintenance cost and training cost. Higher is the benefit-cost ratio, positive is the intention to switch to renewable energy. Minimum investment required to install renewable energy can be higher. Rogers et al. (2008) and West et al. (2010) suggested availing economic incentive to ease the financial burden from the users. However, there are studies, on willingness to pay while using renewable energy as an alternative energy that reported negative opinion from the users' in Australia, United Kingdom, Greece and China. The summary of these studies report that on the average users are reluctant to pay more than $5 \%$ when compared to their existing energy expenses used for conventional energy. This negative attitude may reduce users' intention to switch to renewable energy:

H2: Higher benefit-cost ratio positively correlates with intention to use renewable energy.

Preliminary analysis on cost and investment drive the potential users towards strong intention to purchase the renewable energy technology. However, users extend the analysis to understand whether they have full control over their decision, a choice of technology based on ease of use and perceived usefulness. Theory of planned 
behaviour explains perceived behavioural control of the users' while analysis the extent to which they control the decision regarding the purchase of the new technology. Users' confidence, reliability with the decision under environmental constrains and positive approach towards future use represent higher perceived behavioural control. Hence, it is also clear that perceived behavioural control cannot influence the intention of renewable energy use directly. It mediates attitude towards renewable energy and attitude mediates with intention to use. Marketing programs on renewable technology should highlight the lifestyle of the users and these programs should target actual purchaser:

H3: Stronger perceived behavioural control positively influences attitude towards renewable energy and indirectly influences intention to use renewable energy.

Technology adoption model supports that user accept new technology based on their perceived ease of use. Perceived ease of use is influenced by users' opinion regarding installation, regular use, maintenance and recycling of the new technology. Ease of use is explained from the technical standpoint of renewable energy. Studies perceive that use of solar energy and management of biomass spell out numerous technical barriers to end users. As a result, mass users show disinclination to invest in solar and biomass energy. If the government would like to distribute energy from hydroelectric plants, it would have to manage retail stores and separate distribution system. Stephenson and Loannou argued that family and community friendly renewable technology will positively influence the intention to use renewable energy:

H4: Higher the perceived ease of use, higher is the intention to use renewable energy.

Finally, users compare the existing renewable energy technology with the conventional technologies and make decisions based on an overall socioeconomical view point. Users search for the energy technology that is relatively cheaper, easy to use and offer benefits in the future. Growth of renewable energy usage has been much slower than expected due to lower relative advantage of the new technology compared to easy to use and easy to manage energy solutions. Relative advantage of a new technology includes cost, social impact as well aesthetics and other behavioural factors. Relative advantage is ensured if the new technology offer higher value, designed based on local taste and offer a replacement benefit if the users want to go back to earlier technology. However, relative advantage is influenced by individual attitude. Hence, relative advantage is hypothesised to mediate attitude towards renewable energy and has an indirect relationship with intention to use renewable energy.

H5: Higher relative advantage of renewable energy directly positively influences attitude towards renewable energy and indirectly influences users' intention to use renewable energy.

Technology acceptance model identifies Attitude Towards Using (ATU) as a mediator between behavioural intention to buy and perceived ease of use and perceived usefulness. Theory of reasoned action puts Attitude Towards Behaviour (ATB) as one of the first-stage mediators between beliefs and evaluations and behavioural intention. This study considers the mediating role of attitude towards renewable energy use. Higher benefit-cost trade-off, higher level of awareness and higher ease of use directly influence intention to use renewable energy. Higher relative advantage and higher perceived behavioural control are hypothesised to directly influence intention to use renewable energy.

H6: Attitude towards renewable energy directly mediates the relationship between intention to use and external determinant.

\section{MATERIALS AND METHODS}

Primary objective of this study is to analyse the most influential determinants of attitude of the Malaysian households' towards renewable energy use. Literature review and extensive brainstorming with industry experts have assisted in gathering the conceptual framework, which lead to the eventual data collection. After a brief pre-testing involving twenty sample respondents, a structured questionnaire has been finalised for mass survey.

Table 2. Respondents' profile

\begin{tabular}{llrr}
\hline Variables & & Freq. & $(\%)$ \\
\hline Gender & Male & 81 & 40.5 \\
& Female & 119 & 59.5 \\
& Malay & 146 & 73.0 \\
& Chinese & 27 & 13.5 \\
Ethnic origin & Indian & 16 & 8.0 \\
& Others & 11 & 5.5 \\
& Below 3 rooms & 63 & 31.5 \\
& 3-5 Rooms & 114 & 57.0 \\
Establishment size & 5-10 Rooms & 17 & 8.5 \\
& 10-20 Rooms & 1 & 0.5 \\
& More than 20 rooms & 1 & 0.5 \\
\hline
\end{tabular}

Missing values were ignored, $\mathrm{N}=200$. 
Table 3. Factor analysis outputs

\begin{tabular}{|c|c|c|c|c|c|}
\hline Factors & Statements/variables & Loading & $\begin{array}{l}\text { Var } \\
\text { explained (\%) }\end{array}$ & $\begin{array}{l}\text { Cronbach } \\
\text { alpha }\end{array}$ & Mean \\
\hline \multirow[t]{4}{*}{ Ease of Use } & Easy to install renewable energy materials & 0.821 & 14.73 & 0.918 & 4.146 \\
\hline & Easily understandable manuals & 0.801 & & & \\
\hline & Easy to operate & 0.787 & & & \\
\hline & Easy to master on the operating the machine & 0.777 & & & \\
\hline \multirow[t]{4}{*}{ Awareness } & I can recall what is renewable energy & 0.851 & 13.88 & 0.893 & 4.248 \\
\hline & I am aware of renewable energy & 0.829 & & & \\
\hline & I can recognize the renewable energy easily & 0.786 & & & \\
\hline & Easy to imagine renewable energy & 0.769 & & & \\
\hline Benefit-cost & Additional cost required for training & 0.867 & 11.21 & 0.902 & 4.34 \\
\hline \multirow[t]{2}{*}{ Trade-off } & Difficult to justify cost and benefits & 0.835 & & & \\
\hline & High set up cost & 0.811 & & & \\
\hline Relative & Environmental concern has significant benefits. & 0.798 & 20.79 & 0.927 & 4.609 \\
\hline \multirow{6}{*}{ Advantage } & Environmental involvement matters. & 0.794 & & & \\
\hline & Environmental involvement benefits me a lot. & 0.737 & & & \\
\hline & RE will decrease air pollution & 0.737 & & & \\
\hline & RE will reduce carbon footprint & 0.697 & & & \\
\hline & RE will reduce conventional energy use & 0.693 & & & \\
\hline & RE will offer competitive benefits to my country & 0.613 & & & \\
\hline & I will use RE even if RE is relatively expensive & 0.771 & 15.23 & 0.91 & 4.49 \\
\hline \multirow{5}{*}{ behavioral control } & I will use RE even my friends advise me not to use. & 0.751 & & & \\
\hline & I can difference by using RE & 0.750 & & & \\
\hline & Using renewable energy is entirely within my control & 0.691 & & & \\
\hline & I will buy RE very soon & 0.594 & & & \\
\hline & $\begin{array}{l}\text { I have the resources, knowledge and } \\
\text { ability to use renewable energy }\end{array}$ & 0.578 & & & \\
\hline
\end{tabular}

Note: $\mathrm{KMO}=0.918$, Cumulative Variance Explained $(\%)=75.84 \%$

Table 4. Regression outputs

\begin{tabular}{|c|c|c|c|c|c|c|c|c|c|c|}
\hline \multirow[b]{2}{*}{ Factors } & \multicolumn{2}{|l|}{ Model 1} & \multicolumn{2}{|l|}{ Model 2} & \multicolumn{2}{|l|}{ Model 3} & \multicolumn{2}{|l|}{ Model 4} & \multicolumn{2}{|l|}{ Model 5} \\
\hline & Stnd Beta & Sig & Stnd Beta & Sig & Stnd Beta & Sig & Stnd Beta & Sig & Stnd Beta & Sig \\
\hline Constant & & 0.974 & & 0.820 & & 0.491 & & 0.917 & & 0.470 \\
\hline Attitude & 0.284 & 0.001 & -- & -- & -- & -- & 0.474 & 0.000 & -- & -- \\
\hline Rel. Adv. & 0.023 & 0.724 & 0.136 & 0.026 & 0.397 & 0.000 & -- & -- & 0.418 & 0.000 \\
\hline PBC & 0.168 & 0.006 & 0.264 & 0.000 & 0.335 & 0.000 & -- & -- & 0.346 & 0.000 \\
\hline Ease of Use & 0.326 & 0.000 & 0.363 & 0.000 & 0.130 & 0.026 & -- & -- & -- & -- \\
\hline Awareness & 0.187 & 0.002 & 0.203 & 0.001 & 0.057 & 0.350 & -- & -- & -- & -- \\
\hline Benefit-Cost & 0.103 & 0.074 & 0.104 & 0.081 & 0.005 & 0.930 & -- & -- & -- & -- \\
\hline Adj. $\mathrm{R}^{2}$ & 0.395 & & 0.345 & & 0.341 & & 0.22 & & 0.33 & \\
\hline F Value & 22.662 & 0.000 & 21.966 & 0.000 & 21.613 & 0.000 & 57.287 & 0.000 & 50.01 & 0.000 \\
\hline Dependen & & & & & & & & & & \\
\hline Variable & \multicolumn{2}{|c|}{ Intention to use } & \multicolumn{2}{|c|}{ Intention to use } & \multicolumn{2}{|l|}{ Attitude } & \multicolumn{2}{|c|}{ Intention to use } & Attitude & \\
\hline
\end{tabular}

Table 5. Test for significance for indirect relationship

\begin{tabular}{|c|c|c|c|c|}
\hline & \multicolumn{2}{|l|}{$\begin{array}{l}\text { Relative } \\
\text { advantage }\end{array}$} & \multicolumn{2}{|c|}{$\begin{array}{l}\text { Perceived } \\
\text { behavioural control }\end{array}$} \\
\hline & $\begin{array}{l}\text { All Xs' with } \\
\text { Mediator* }\end{array}$ & $\begin{array}{l}X>>> \\
\text { Mediator }\end{array}$ & $\begin{array}{l}\text { All Xs' with } \\
\text { Mediator }\end{array}$ & $\begin{array}{l}X>>> \\
\text { Mediator }\end{array}$ \\
\hline$\overline{\text { Beta }}$ & 0.286 & 0.345 & 0.286 & 0.325 \\
\hline Standard error & 0.069 & 0.053 & 0.069 & 0.057 \\
\hline Sobel $Z$ & 3.496 & 3.353 & & \\
\hline $\mathrm{p}$ Value (Two tailed) & 0.000 & 0.000 & & \\
\hline
\end{tabular}

Based on the conceptual framework, the questionnaire includes perception related questions that use 6-points response scale. In the scale, ' 1 ' was used when respondents strongly disagree with the statement while ' 6 ' was used for the other extreme. Hypotheses planned to be tested in this study involve constructs that should be tested using proxies. Hence, a number of statements were included in the questionnaire to analyse the constructs. 


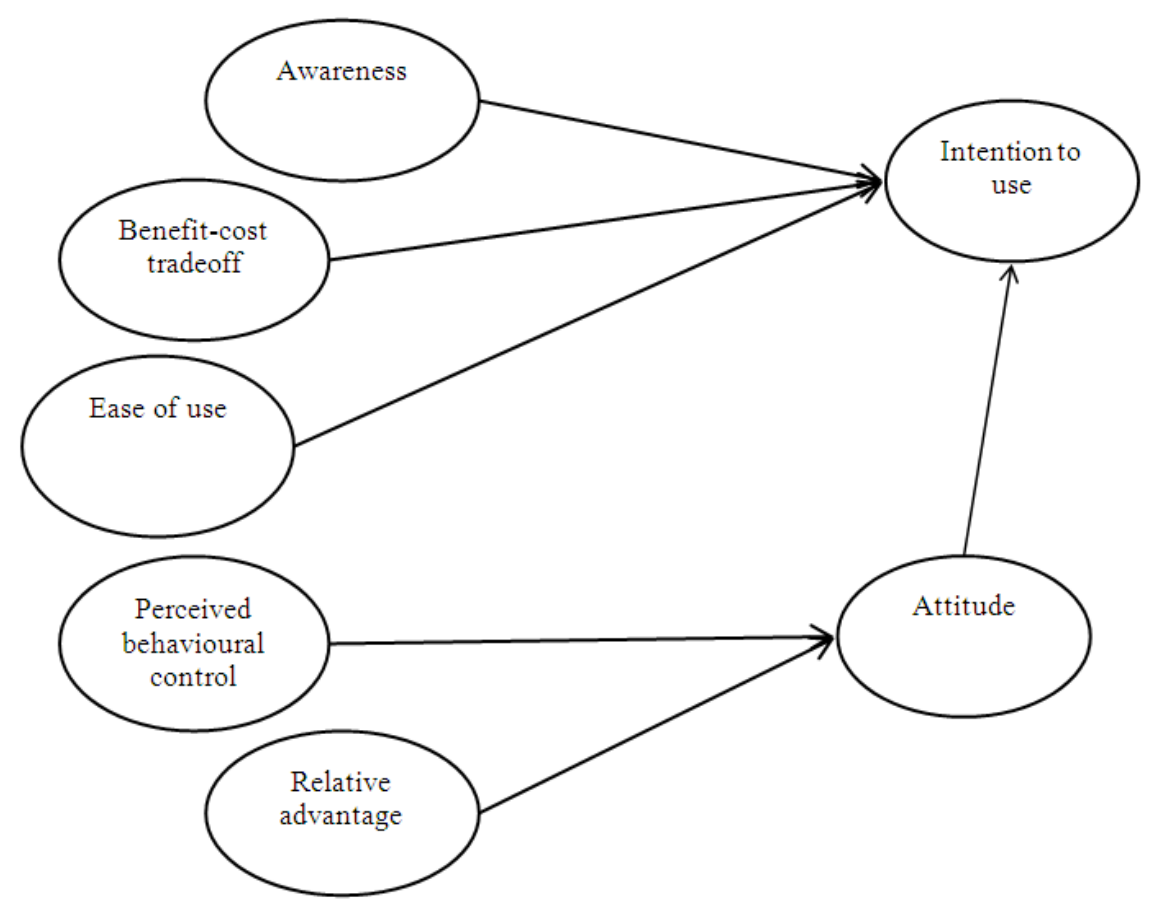

Fig. 3. Conceptual framework

Total 27 such statements were given in the questionnaire for respondents' opinion.

Households' use of renewable is still in emerging stage in Malaysia. Therefore, it was difficult to get any sampling profile. Consequently, the study followed a snow-ball sampling method. Under this method, researchers collect respondents' information from other respondents. Since, the study uses non-parametric sampling method, results of this study theoretically generalises the objectives among Malaysians. Data collection continued until the researchers found a theoretical situation in respondents' opinion and demographic characteristics of the respondents came close to the official statistics in Malaysia. Table 2 shows demographic characteristics such as the gender, ethnic origin and size of the establishment. Around $60 \%$ of the respondents were female, $73 \%$ of them were Malay origin and around $88 \%$ of them were having at most five rooms or below in their houses.

Data were analysed in three steps. Factor analysis was used to extract common theme from a number of statements. Principal component analysis was component was used alongside varimax rotation as the theoretical framework does not assume any co-relation among the constructs. Table 3 reports the rotated component matrix with minimum factor loading of 0.50 . Sampling adequacy and reliability of the constructs were tested using Kaiser-
Mayer-Olkin (KMO) statistics and Chronbach alpha. A minimum of $0.7 \mathrm{KMO}$ statistics is expected to meet satisfactory sampling adequacy. Nunnally (2010) supported a minimum alpha value of 0.70 . Factor outputs were saved using Anderson-Rubin method built into SPSS 19, which converts the outputs into a standardised normal distribution with mean equals zero and variance equals one.

Factor outputs from factor analysis were used to conduct multiple regression analysis to obtain a theoretical framework depicted in Fig. 3. Attitude towards renewable energy is the mediator. Thus, regression analysis must show direct and indirect relationship as depicted in Fig. 3. Relative advantage and perceived behavioural control have indicate effect on intention to use mediated by attitude towards renewable energy. Benefit-cost trade-off, awareness and ease of use show a direct effect on intention to use renewable energy. Baron and Kenny (1986) suggested a four steps methodological solution for testing for mediation. Let's consider these effects as paths. Path ' $\mathrm{C}$ ' goes from determinant constructs to dependent constructs to intention to use. Path ' $A$ ' goes from determinants to mediator attitude towards renewable energy. Path ' $\mathrm{B}$ ' goes from mediator to intention to use. According to Baron and Kenny (1986) analysis should follow path ' $C$ ', ' $A$ ' and path ' $B$ '. If all these three are significant, then one more step will be needed to conclude whether 
mediating is possible or not. This last stage involves all the determinants and mediating variables used to regress against dependent variable. However, these famous four steps did not provide statistical significance to the indirect effect.

Sobel (1982) presented a significance test for the indirect effect involving determinants, mediating variables and the dependent variable. This approach is also called the Sobel (1982) product of coefficients approach. In this approach, $B_{\text {indirect }}=B_{2} \times B$. Here, $B_{2}$ is the unstandardized beta coefficient of mediator with dependent variable when conducting regression involving all independent determinants, mediator and dependent variable. $B$ is the unstandardized beta coefficient of independent variables predicting the mediator variable. After the result of Beta Indirect is obtained, significance of the beta was checked using online software available at http://www.danielsoper.com/statcalc3/calc.aspx?id=31. Sobel (1982) test statistics is $\mathrm{Z}=\frac{\mathrm{ab}}{\left(\mathrm{b}^{2} \mathrm{SE}_{\mathrm{a}}^{2}\right)+\left(\mathrm{a}^{2} \mathrm{SE}_{\mathrm{b}}^{2}\right)}$ and follows normal distribution. Here, ' $a$ ' represents coefficient for the relationship between the independent variables and the mediator, ' $b$ ' refers to coefficient for prediction using mediator and dependent variable. 'SEa' presents the standard error of the relationship between mediator and independent variables and 'SEb' shows the standard error of the relationship between dependent variable and mediator. Table 4 and 5 show the results of multiple regression models and significance tests for indirect relationship.

\section{RESULTS}

Factor analysis in Table 3 shows five factors with their respective factor loading, variance explained, mean and reliability statistics. The analyses reveal outstanding KMO statistics of 0.918 ; cumulative variance explained of $75.84 \%$ is median in management research. Relative advantage and perceived behavioural control collectively explained half of the total variance explained by all five factors. These two factors are the most important two factors in terms of the mean values. Their mean values are 4.6 and 4.49 respectively. Cronbach alpha values of all the factors are way higher than the satisfactory limits.

Table 4 shows the regression models with and without mediating terms. It shows step-by-step whether mediation is possible or not. Five models are being tested. The left most column shows the factors, which includes attitude, the mediator, two indirect factors, relative advantage and perceived behavioural control and three direct factors, ease of use, awareness and benefit- cost trade off. Model 1 includes all the determinant factors alongside the mediator and intention to use as the dependent variable. With a higher level of Adjusted R Squared, the model shows insignificant coefficient of relative advantage. However, attitude, the mediator, was significant at $1 \%$ level. Model 2 finds all the independent variables, except the mediator, significant (at the maximum of $10 \%$ level of one variable).

Model 3 shows that two direct factors, awareness and benefit-cost trade-off, become insignificant when regressed with attitude, the mediator, as the dependent variable. Ease of use becomes significant with and without mediator as the dependent variable. The study hypothesised ease of use having a direct impact on intention to use renewable energy. Model 4 shows that the mediating variable, attitude, carries a positive relationship with intention to use renewable energy. Finally, model 5 reports that two indirect variables, relative advantage and perceived behavioural control, carry better relationship with mediating variable, attitude, when compared with intention use as the dependent variable. These five models lend support to the six hypotheses offered in this study. To accomplish the test of significance of indirect relationship, Table 5 shows the Sobel (1982) test statistics and 'p' values.

Under Sobel (1982) test, testing for the significance of individual indirect relationship was conducted one variable at a time. The study has two indirect variables: Relative advantage and perceived behavioural control. For the both the variables, Sobel (1982) Z score is significant at $1 \%$ level. These results indicate that there is attitude is a significant mediator between the two indirect variables to intention to use renewable energy. Our results are partially supported by Technology Acceptance Model. In TAM, ease of use is an indirect variable to influence behavioural intention mediated by attitude. However, usefulness, a proxy of relative advantage, is reported having indirect relationship with intention. Theory of planned behaviour and theory of reasoned action give support to this study. The study is the first of its kind using theory of reasoned action and theory of planned behaviour in renewable energy use in Malaysia. Hence, it was not possible to compare results with other studies. This part of the limitation we leave for future research.

\section{DISCUSSION}

Various western literatures support the findings of this study. Higher relative advantage and stronger perceived behavioural control positively influences attitude towards renewable energy use. Awareness, technical know-how (ease of use) and low cost positively influences intention to use renewable energy. 
Government and private companies that are responsible for marketing renewable energy technologies to households may capitalise on the findings of this study. Specialised marketing and training programs can be organised to train and educate the communities on the technical know-how and social use of the renewable energy technologies. Economic incentives from the government may ease the adoption to new technology.

Finally, lack of studies on attitude towards renewable energy use in emerging nations increases the risk from understanding the nature of behaviour from the potential users. This study was undertaken to understand what users' value when they think about purchasing renewable energy technology in Malaysia. Using factor analysis and multiple regression analysis on the data collected from 200 respondents, this study finds that there are direct and indirect factors influencing intention to use renewable energy. Three significant direct factors are level of awareness, benefit-cost trade-off and higher ease of use. Two indirect factors are relative advantage and perceived behavioural control. The indirect factors mediate attitude towards renewable energy and attitude mediates intention to use. Theory of reasoned action and theory of planned behaviour lend support to the findings of the study. Government and private companies can design training and marketing programs to educate communities on the use of renewable energy to ease the adoption process.

\section{CONCLUSION}

The analytical results of our study confirmed the mediating role of attitude. More specifically, attitude towards renewable energy usgae have significant relationship with intention to use renewable energy usage. The analytical results are generally consistent with previous studies. It would be interesting to study the same factors in connection to renewable energy usage pattern by on a different, more average renewable nergy user population.

\section{REFERENCES}

Ajzen, I., 2002. Perceived behavioral control, selfefficacy, locus of control and the theory of planned behavior. J. Applied Soc. Psychol., 32: 665-683. DOI: $10.1111 /$ j.1559-1816.2002.tb00236.x

Ajzen, I., 1991. The theory of planned behaviour. Organ. Behav. Hum. Dec. Proc. 50: 179-211. http://people.umass.edu/psyc661/pdf/tpb.obhdp.pdf

Baron, R.M. and D.A. Kenny, 1986. The moderatormediator variable distinction in social psychological research: Conceptual, strategic and statistical considerations. J. Personality Soc. Psychol., 51: 1173-1182. DOI: 10.1037/0022-3514.51.6.1173

Fishbein, M. and I. Ajzen, 1975. Belief, Attitude, Intention and Behaviour: An Introduction to Theory and Research. 1st Edn., Addison-Wesley Pub. Co., Reading, Mass., ISBN-10: 0201020890, pp: 480.

Fredric, B. and E. Martinot, 2004. Renewable Energy Policies and Barriers. In: Encyclopedia of Energy, Cleveland, J. and R.U. Ayres (Eds.), Elsevier Academic Press, Amsterdam, ISBN-10: 0121764834, pp: 365-383.

Nunnally, J.C., 2010. Psychometric Theory. 3rd Edn., Tata McGraw-Hill Education, New Delhi, ISBN-10: 0071070885, pp: 752.

REN21, 2011. Renewables Global Status Report. REN21, Paris.

Rogers, J.C., E.A. Simmons, I. Convery and A. Weatherall, 2008. Public perceptions of opportunities for community-based renewable energy projects. Energy Policy, 36: 4217-4226. DOI: 10.1016/j.enpol.2008.07.028

Sobel, M.E., 1982. Asymptotic confidence intervals for indirect effects in structural equation models. Sociol. Assoc., 13: 290-312. DOI: 10.2307/270723

West, J., I. Bailey and M. Winter, 2010. Renewable energy policy and public perceptions of renewable energy: A cultural theory approach. Energy Policy, 38: 5739-5748. DOI: 10.1016/j.enpol.2010.05.024 